\title{
Recoverability of Deletion ${ }^{*}$
}

\author{
Kyle Johnson \\ University of Massachusetts at Amherst
}

December 3, 2012

\begin{abstract}
This paper provides an analysis of Andrews amalgams that builds on work by Marlies Kluck and Maxamiliano Guimaräes. It argues that Andrews amalgams involve bringing two independent sentences together by sharing a clause, where "sharing" is modeled by giving a phrase two mothers in a phrase marker. Andrews amalgams are licensed by Sluicing: they occur only when the shared clause can be sluiced. This, it is argued, shows us that the licensing conditions on ellipsis do not necessarily invoke the antecedence conditions usually attendant with ellipsis.
\end{abstract}

${ }^{*}$ My thanks to Marlies Kluck for teaching me everything about amalgams, and to Vidal Valmala Elguea for a careful and insightful critique of the paper. His many ideas could fill an additional (and better!) paper on this subject. I've also been helped by discussions with Rajesh Bhatt, Luis Vicente, Michal Starke and Uli Sauerland. 


\section{Introduction}

There is a trivial observation about Ellipsis which should follow from whatever ingredients license it. That observation is what Katz and Postal (1964) called the Recoverability Condition on Deletion, and it is elegantly argued for in Fiengo and Lasnik (1972). It amounts, simply, to the observation that a phrase cannot elide unless there is an antecedent for that phrase. A theory of ellipsis should guarantee that an elided phrase is understood as an anaphor, then, and we should also hope to have a successful account of how that anaphora is resolved: the antecedence conditions on ellipsis.

One way of ensuring that elided material be recoverable is to build it into the ellipsis process itself. That is presently the most popular view, with a couple types of execution. One execution builds on the idea that an elided phrase is a kind of word. As a word, it has a particular denotation and a particular morphology. The morphology is silence, and the denotation is whatever it is that its antecedence conditions require. The idea that ellipsis is a kind of silent word is found in many places. A good extended explication of the idea, with references to many of the others, is in Hardt (1992). Another execution has many of the same features as the silent word idea, but allows for ellipsis to be a phrase with internal structure. This approach comes from Merchant (2001), who suggests that elided phrases are permitted only when they are in construction with a licensing head. (The idea that ellipses are licensed by nearby heads has antecedents in Zagona (1988b,a) and Lobeck (1987a,b, 1992).) The heads that license ellipsis are responsible, on Merchant's proposal, for specifying how the elided phrase is pronounced and semantically interpreted. He suggests that these heads are equipped with a feature - an "e-feature" - which says that its complement phrase is silent and has the denotation required to produce the requisite antecedence conditions. Just like the pronoun approach, then, the e-feature bundles the properties of silence and anaphora that ellipsis seems to combine. The salient difference with the pronoun approach is that it allows the elided phrase to continue to be a phrase, and not a word.

Both the pronoun approach and the e-feature approach have the virtue of allowing elided phrases to invoke a specific set of antecedence conditions. The e-feature or pronoun can be equipped with a denotation that is built specifically for the case of ellipsis. That is a virtue because the antecedence conditions for ellipsis are not known to be identical to any invoked by other anaphors. Many treatments of ellipsis follow Tancredi (1992), and attempt to relate the antecedence conditions on ellipsis to those on deaccented material. ${ }^{1}$ But there are several differences between those conditions that have not been resolved. At present, then, the antecedence conditions on ellipsis appear to be proprietary. To the extent that this is true, it supports the view that they

1 See Rooth (1992) and Merchant (2001) for two prominent examples. 
should be built into the denotation of the ellipsis, or its licensor, in the ways just described.

If, however, the antecedence conditions on ellipsis could be reduced in full to some other form of anaphora - say, for instance, to the antecedence conditions that hold of deaccented material - then we could entertain a second possibility. We could see ellipsis as invoking no special antecedence conditions at all. All there would be to ellipsis is whatever it is that licenses the ellipsis of certain constituents. How those ellipses gain the meanings they do would follow from a general condition on the recoverability of deletion. Tancredi (1992) is a proponent of this view, and it is given an extended defense in Fox (2000). They argue that the conditions on deaccented material are, by themselves, able to distinguish ellipses from spoken, but deaccented, strings.

This paper argues for the second view. I will discuss a case of ellipsis in which there is no antecedent, and consequently no antecedence conditions whatsoever are invoked. Ellipses do not always induce antecedence conditions, then. In the cases we will see, the licensor for ellipsis allows the elided clause to be displaced: to be literally spoken somewhere unexpected. A licensor for ellipsis should therefore be thought of as an instruction about how to pronounce a certain phrase. It amnesties that phrase from being pronounced in the "normal" position. When that happens and the result is no pronunciation of the phrase at all, a meaning must be recovered to furnish the rest of the sentence with enough content to produce a denotation. In that case, an antecedent is required, and the antecedence conditions kick in. However, when a licensor amnesties a phrase from being pronounced in the normal position and the result is an alternative placement for the pronunciation of the phrase, there is no need for an antecedent. That is what we will see.

Where we will see it is in "Andrews amalgams." After sketching an account of Andrews amalgams, we will look at the central use they make of the licensing condition on Sluicing. There is no anaphora in an Andrews amalgams, however, and so no invocation of antecedence conditions. They are a construction in which an ellipsis process is invoked, but not the antecedence condition which normally accompanies ellipsis.

\section{Andrews Amalgams}

Lakoff (1974) introduced sentences like (1), and credited their discovery to Avery Andrews. I will follow Kluck (2011) and call them "Andrews amalgams."

(1) Sally will eat [I don't know what] today.

The peculiarity of (1) that makes it interesting is how the bracketed clause (the "interrupting clause") manages to function as the object of the verb, ate, in the "hosting 
clause." We need to find a way of giving (1) a syntax that allows it to have a meaning parallel to (2).

(2) Sally will eat something today but I don't know what.

Marlies Kluck and Maxamiliano Guimaräes wrote dissertations in the last few years that provide very complete analyses of Andrews amalgams, and my discussion will take their work as a starting point. ${ }^{2}$ Two properties of Andrews amalgams that help steer us towards an account are, first, that the interrupting clause has the word order characteristic of root clauses. This is indicated, among other things, by the fact that they must have verb second word order in those languages, like Dutch, where that is required of root clauses.

(3) a. Bob heeft [je raadt nooit hoeveel koekjes] gestolen.

Bob has [you guess never how many cookies] stolen

(Bob has stolen you'll never guess how many cookies.)

b. * Bob heeft [je nooit hoeveel koekjes raadt] gestolen.

Bob has [you never how many cookies guess] stolen

(Bob has stolen you'll never guess how many cookies.)

(Kluck 2011, (14): 55)

A companion fact is that most of the interrupting clause is not in the scope of material in the host clause. This can be appreciated by seeing that a pronoun in the interrupting clause cannot function as a variable bound by a quantifier in the host clause ((4a) is ungrammatical) and a name in the interrupting clause does not trigger disjoint reference effects with material in the host clause $((4 \mathrm{~b})$ is grammatical).

(4) a. * Almost every student 1 kissed [he ${ }_{1}$ didn't even remember how many classmates].

b. ? $\mathrm{He}_{1}$ had been kissing [the professor ${ }_{1}$ (himself) didn't even remember how many students]. compare:

${ }^{*} \mathrm{He}_{1}$ had been kissing many students that the professor ${ }_{1}$ (himself) didn't remember.

(based on Kluck 2011, (170): 97 \& (195): 102)

2 See Guimarães (2004) and Kluck (2011). Kluck puts Andrews amalgams together with "Horn amalgams," illustrated in (i).

(i) Sally ate [I think it's natto] yesterday.

My focus will be on Andrews amalgams, and the account I will provide does not trivially extend to Horn amalgams. Since part of my goal will be to explain where amalgams are possible, that is a serious shortcoming and it should be kept in mind. 
These facts lead to the conclusion that the interrupting clause and the clause it interrupts are, in some sense, two independent sentences. That also corresponds to the fact that the interpretation we aim for conjoins these two clauses, as (2) does.

On the other hand, Kluck shows that the interrupting clause is positioned syntactically within the host clause in just the places that it should be if it were fulfilling the semantic role that it seems to fulfill. In (1), for instance, it seems to provide the object of ate, and it can be in just the places that objects can be in this sentence.

(5) a. i. Sally will eat [I don't know what] today.

ii. Sally will eat [the rutabagas] today.

b. i. Sally will eat today [I don't know what].

ii. Sally will eat today [the rutabagas].

c. i. * Sally will [I don't know what] eat today.

ii. * Sally will [the rutabagas] eat today.

And when an interrupting clause seems to provide the object of a preposition, it can only be in the position that objects of prepositions can be.

(6) a. i. Sally stepped into [I won't say what] on her way home.

ii. Sally stepped into [the nattoo pot] on her way home.

b. i. * Sally stepped into on her way home [I won't say what].

ii. * Sally stepped into on her way home [the nattoo pot].

c. i. * Sally stepped [I won’t say what] into on her way home.

ii. ${ }^{\star}$ Sally stepped [the nattoo pot] into on her way home.

And when an interrupting clause seems to play the role of an adjective, it can only appear in the positions that adjectives can.

(7) a. i. Sally ate [I don't know how smelly] a dinner.

ii. Sally ate [so smelly] a dinner.

b. i. * Sally ate a dinner [I don't know how smelly].

ii. * Sally ate a dinner [so smelly].

c. i. Sally became [I don't know how sick] yesterday.

ii. Sally became [so sick] yesterday.

d. i. * Sally became yesterday [I don’t know how sick].

ii. ${ }^{\star}$ Sally became yesterday [so sick].

We therefore want the interrupting clause to be enough a part of the hosting clause syntactically that we can use the normal syntax to determine its position. 
One way of doing that would be to let a part of the interrupting clause be in the hosting clause, but leave all the rest of it outside. Riemsdijk (1998, 2000, 2006), Wilder (1998), and Guimarães (2004) suggest doing that with multidominant phrase markers. This would give to (1) a representation something like (8).

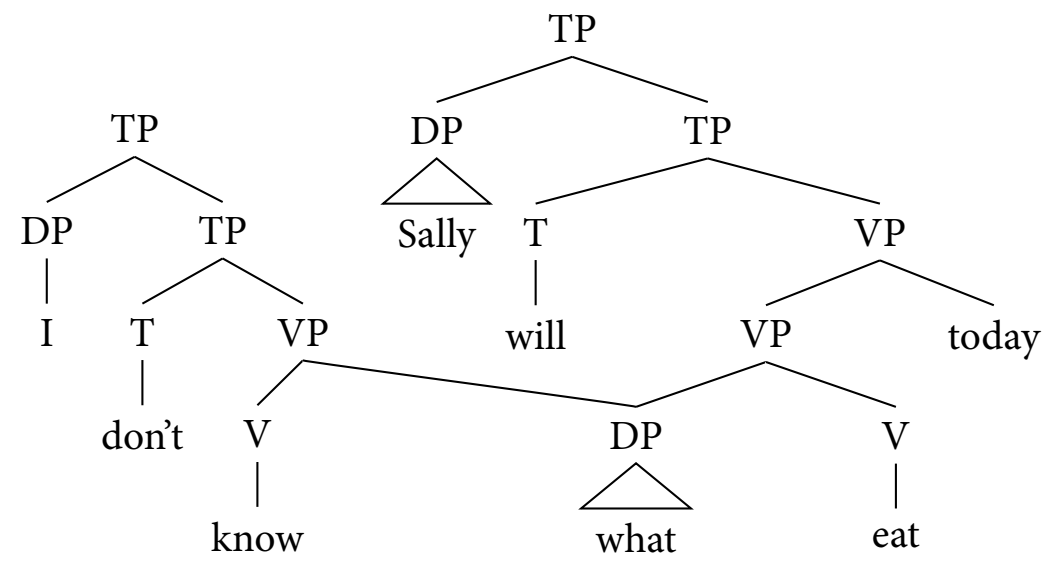

Then we could rely on the linearization scheme's desire to map phrases onto contiguous strings to put all of the interrupting clause where the shared material is.

Imagine, for concreteness, that there is a violable constraint on the linearization of syntactic structures of the form in (9).

\section{(9) Contiguity}

Assign a violation mark to a phrase if the strings assigned to each of its immediate daughters do not have an adjacent edge.

Contiguity requires that phrases map onto contiguous strings of formatives. This is sometimes violated (as when movement applies), but Contiguity will otherwise enforce it. Let us assume that the linearization of a phrase marker satisfies Contiguity as best as it can, minimizing its violation. Contiguity, then, will be violated only to the extent required by other properties of the phrase marker being linearized. Contiguity will force the interrupting clause to be adjacent to the shared material.

To see why, consider how Contiguity will judge the two strings in (10). (Throughout, I will assume that the principles responsible for linearizing English phrase markers do the right thing; that is, they put heads and Specifiers first.)

(10) a. Sally $[\text { should }]_{a}[\text { [eat }]_{b}\left[\text { I don't }[\text { know }]_{c}\right]_{b, c}[$ what $\left.]\right]$ today

b. Sally $[\text { should }]_{a}\left[\text { I don't }[\mathrm{know}]_{c}\right]_{a}\left[[\text { eat }]_{b} b, c[\right.$ what $\left.]\right]$ today

I've bracketed constituents that are sisters and attached matching labels to their edges. The grammatical string, (10a), has one violation of Contiguity: what is not adjacent to eat and that causes the VP headed by eat to be assigned a violation mark. (1ob), 
by contrast, has two violations of Contiguity: know is not adjacent to what, causing its VP to get a violation mark, and should is not adjacent to the VP headed by know, causing the IP which should heads to receive a violation mark. As this comparison highlights, the best place for the interrupting clause will be adjacent to the shared material. That incurs a violation of Contiguity by separating the shared material from its other sister, but because the shared material has two sisters, there is no yavoiding one violation of Contiguity. Putting the interrupting clause anywhere else will not only separate it from the shared material, thereby invoking the unavoidable violation of Contiguity, it will also cause two other sisters to be separated. Thus, the best place for the interrupting clause will be adjacent to the shared phrase; this is the only spot that incurs no unnecessary violations of Contiguity. ${ }^{3}$

Adopting (8), then, provides a way of accounting for where the interrupting clause gets linearized. There are other facts which can be construed as evidence for (8) as well. ${ }^{4}$ For one thing, the shared material, unlike the rest of the interrupting clause, does seem to be within the scope of stuff in the hosting clause. Unlike what we saw in (4), a quantifier in the hosting clause can bind a pronoun in the shared material ((11a) is grammatical), and a name in the shared material does invoke disjoint reference effects with material in the hosting clause ((11b) is ungrammatical).

(11) a. Almost every student ${ }_{1}$ kissed [you can't imagine how many of his ${ }_{1}$ classmates].

(based on Kluck 2011, (169): 97)

b. $\quad{ }^{*} \mathrm{He}_{1}$ kissed [I don't know how many of the professor ${ }_{1}$ 's students].

That follows from (8) because (8) puts the wh-phrase inside the hosting clause, and therefore within the scope of the material it contains.

The central problem with (8) is that the shared material, the wh-phrase, seems to make different semantic contributions to the hosting clause and the interrupting clause. In the interrupting clause, the wh-phrase is part of a sluice. The what in (8) is

3 With one exception: the very front of the sentence. Kluck shows that this position is unavailable for the interrupting clause even when that would put it adjacent to the shared material. So something independent rules out this option. (I will connect this to (48).)

4 Uli Sauerland raises an interesting problem that speaks against (8), however. He observes that an elided VP can find its antecedent in an Andrew's amalgam, and when it does, it doesn't seem to distinguish the two VPs in it that (8) claims exist.

(i) Sally ate I don't know what yesterday, and Jill did too.

The second conjunct of (i) has the meaning: and Jill ate I don't know what yesterday, too. I suspect this is because neither of the independent VPs in (8) are salient enough to act as antecedents for an ellipsis (see Hardt and Romero (2004) for an account of saliency), and so the ellipsis is resolved by creating an antecedent from the information in both VPs (See Webber (1978) for a parallel case and an account). 
not the object of know, but the remnant wh-phrase of an embedded question that has been sluiced. Kluck (2011) makes an excellent case for this. Among other things, we find the characteristic "form matching" facts that are indicative of ellipsis. ${ }^{5}$ The morphological form of the wh-phrase in a sluice matches that which would be found from its putative source.

(12) a. Er will jemandem schmeicheln, aber sie wissen nicht wem. he will somone-dat flatter, but they know not who-dat (They will flatter someone, but they don't know who.)

b. * Er will jemandem schmeicheln, aber sie wissen nicht wen. he will somone-dat flatter, but they know not who-acc (They will flatter someone, but they don't know who.)

And the same is true in precisely the same way of Andrews amalgams.

(13) a. Bea wollte [ich weiss nicht mehr wem] schmeicheln. Bea wanted [I know not anymore who-dat] flatter (Bea wanted to flatter I don't know who.)

b. ${ }^{\star}$ Bea wollte [ich weiss nicht mehr wen] schmeicheln. Bea wanted [I know not anymore who-acc] flatter (Bea wanted to flatter I don't know who.)

(Kluck 2011, (83): 184)

To put the sluice in (8), we'd have to embrace something like (14).

(14)



We want the hosting clause to mean something like "Sally ate something." So what must be interpreted as "something" in the host clause. But in the interrupting clause, that very same what must be interpreted as, well, "what." That's the problem.

5 This is an argument found in Ross (1969) and extended in Merchant (2001). 
Kluck (2011) proposes a solution to this problem that builds on Tsubomoto and Whitman (2000). She points to examples like (15), which has many of the same characteristics as Andrews amalgams.

(15) Sally ate something - I don't know what - yesterday

(Kluck 2011, p. 293ff)

The parenthetical clause in (15) also acts as if it isn't within the scope of the hosting clause. Building on an unpublished manuscript by Jan Koster, and on the program developed in Mark de Vries's dissertation and subsequent papers, ${ }^{6}$ Kluck suggest that there is a special MERGE operation that joins otherwise independent clauses to material in the host clause. This special form of MERGE does not subordinate the embedded clause in a way that scopal phenomena, like variable binding, are sensitive to. For (15), we might have the representation in (16).

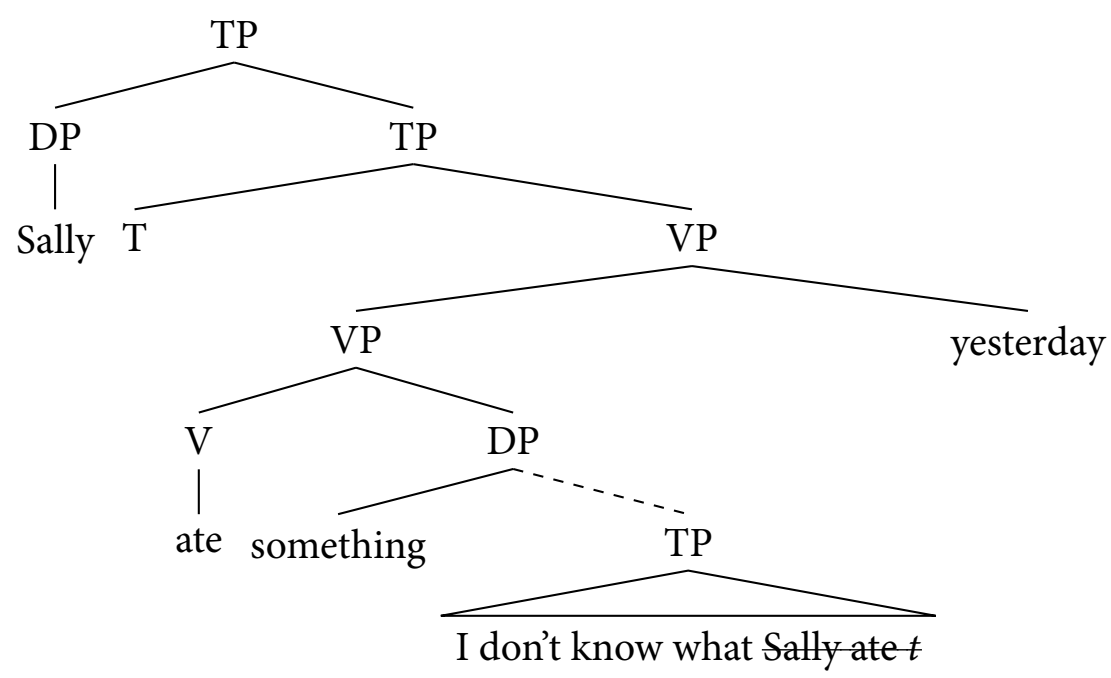

The dashed line is meant to signify the special form of MERGE involved here. An Andrews amalgam, Kluck suggests, is essentially (15), but with a silent object. If we represent the silent object with "e," then (1) would have the structure in (17).

6 See de Vries (2006), for instance. 
(17)

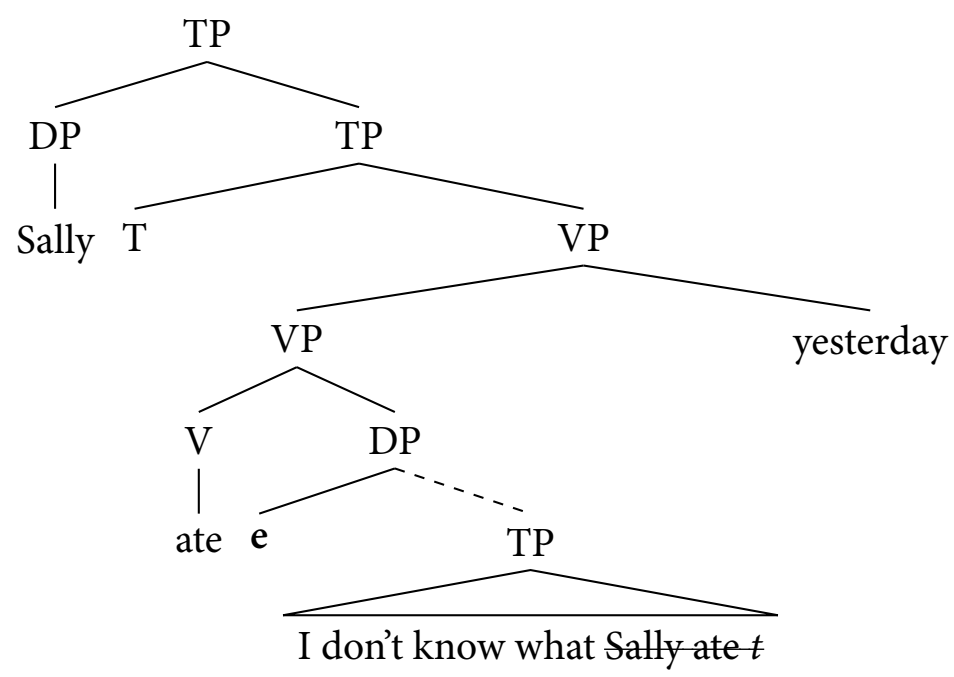

What this structure approximates, then, is something like what is happening in (18).

(18) Sally ate, but I don't know what.

In (18) too, there is an implicit object of ate, and we might equate that implicit argument with “e." On Kluck's view, Andrews amalgams are just (18), but with the special instance of MERGE responsible for bringing the two clauses together.

How does this capture the fact that the shared material, and only the shared material, in the interrupting clause seems to be within the scope of the hosting clause? This, Kluck argues, follows from the fact that the shared material has been moved out of an elided clause that is identical to the hosting clause. Thus, because movement induces reconstruction effects (see (19)), it will appear as if the shared material is in the scope of the hosting clause when it is actually only within the scope of the partially elided interrupting clause.

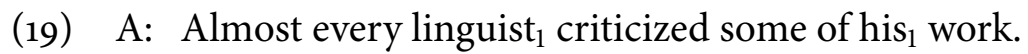

B: Sure, sure: but you're not saying how much of his ${ }_{1}$ work almost every linguist $_{1}$ criticized.

(based on Kluck 2011, (3): 172)

On this view, (11a) would get the representation in (20), and reconstruction would explain why his can be bound by almost every linguist. 




A problem for Kluck's analysis is that the implicit argument in (18) has properties that are not found in Andrews amalgams. First, implicit arguments of the sort found in (18) are sensitive to the verb they are arguments of. Some verbs do not allow their arguments to be implicit. The direct object of send, for instance, cannot be silent. 
(21) * Sally sent to Mary.

compare: Sally sent something to Mary.

But an Andrews amalgam is licit in these cases.

(22) Sally sent [I don't know what] to Mary.

The silent argument that is needed for the Andrews amalgam in (22) needs to be blocked in (21). An Andrews amalgam can be anywhere an overt DP, AP or PP can be, whereas implicit arguments are in a much narrower range of cases. These don't look like the same thing.

Second, although the implicit object in (18) is interpreted as an existentially quantified variable, its existential force cannot out-scope anything else in the sentence. Thus, in (23) the existential quantifier binding the implicit object is necessarily within the scope of negation.

(23) Sally can't eat.

$\approx$ Sally can't eat anything.

For this reason, Sluices are not licensed by antecedents whose implicit argument is in the scope of negation. ${ }^{7}$

(24) * Sally can't eat and I don't know what.

But this is not the case for Andrews amalgams.

(25) Sally can't eat [I don't know what].

$\approx$ There's something Sally can't eat and I don't know what that is.

I think these facts teach us that there is no implicit argument introduced into the host clause by the interrupting clause. The term that is understood as "something" in the host clause is not a silent existential to which the interrupting clause is joined.

Instead, I want to explore the idea that the term which is understood as "something" in the host clause is just the shared wh-phrase. That will mean that the shared whphrase gets a different interpretation in the hosting and interrupting clauses. I believe we should embrace the apparently problematic conclusion that the shared wh-phrase gets a different interpretation in each of the clauses it stands in. What we need to do is understand how a wh-phrase is capable of getting different interpretations.

That a wh-phrase can have two meanings is, in some sense, uncontroversial. When a wh-phrase moves, it must involve two interpretations. If we adopt the remerge theory of movement, a constituent question gets a representation like that in (26). 
(26)

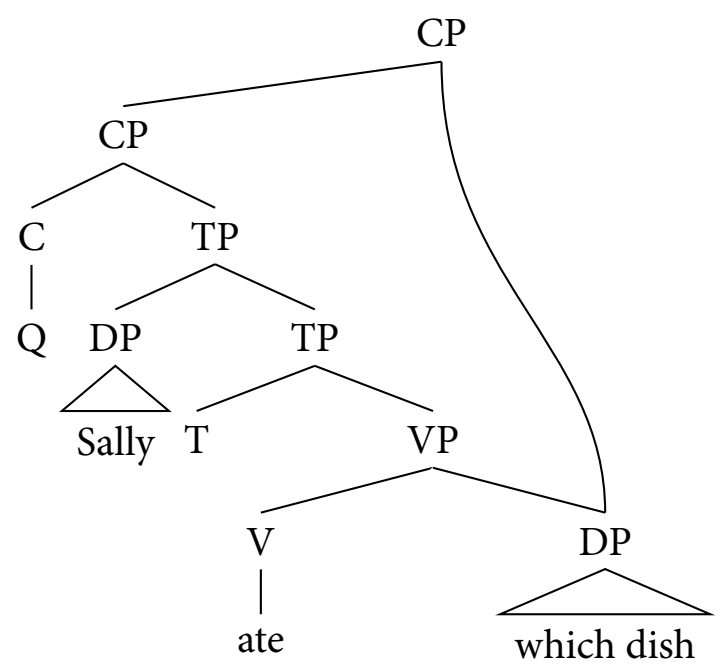

The wh-phrase is in two positions, though pronounced in English only in the higher of these. We want it to introduce a variable in the lower position that is bound by something near the higher position. In many languages, we can see that the variable that a wh-phrase invokes is bound by a functional head. In Japanese, for instance, where wh-phrases are pronounced in their lower position, we can see that what binds the variable introduced by that wh-phrase depends on what nearby functional heads there are. In (27), for example, dono gakusei ('which student(s)') functions as the variable-part of a constituent question.

(27) (Kimi-wa) dono-gakusei-ga nattoo-o tabe-tagatte-iru-to (you-top) which-student-nom natto-acc eat-desirous-be-C omoimasu-ka?

think-Q

(Which student do you think wants to eat natto?)

That is because the question complementizer $k a$ binds that variable. In (28), however, dono gakusei is a variable bound by the universal quantifier mo.

(28) [dono gakusi-ga syootaisita sensi]-mo odotta.

[which student-nom invited teacher]-mo dance

(The teacher that every student invited dance.)

(Shimoyama 2006, (1b): 139)

A nice way of unifying English with these languages is to let the silent Q complementizer bind the variable introduced by which dish in (26). This means that which dish cannot be semantically interpreted in its higher position, and the denotation that 
wh-phrases have in English is, like the interpretation of dono-phrases in Japanese, just an open variable which gets closed by some local operator. ${ }^{8}$

Note, then, that a phrase which resides in two positions, as which dish does in (26), need be semantically interpreted in only one of those positions. The normal requirement that everything in a syntactic representation must be interpreted by the semantic component must be allowed to permit (29).

(29) If a term is in more than one position in a phrase-marker, it need be semantically interpreted in only one of them.

There is a difference between English and Japanese style languages, and that's that the wh-phrases of English can only show up when they are bound by the Q morpheme. Unlike Japanese, wh-phrases in English are not capable of getting their quantificational force from some other operator. We can describe this difference between English and Japanese with (30).

(30) The Question morpheme in English must be pronounced as the determiner of the DP it binds.

Whether (30) holds in a language or not might correlate with whether the functional heads which act as binders are overtly pronounced. ${ }^{9}$ They are in Japanese, but they are not in English. If so, (30) might be seen as a reflex of the more general Principle of Full Interpretation. ${ }^{10}$

(31) Principle of Full Interpretation

Every terminal in a phrase marker must have a morphological reflex.

In this case, the $\mathrm{Q}$ morpheme has its morphological reflex in the determiner. I'll follow Adger and Ramchand (2005), Kratzer (2005) and Cable (2010) and take this to happen through the agency of Agreement. Cable (2010) argues for a locality condition on the Agreement relation which can be seen as the cause for the wh-phrase's movement. Q and the determiner it Agrees with must be essentially adjacent to each other, on Cable's view. ${ }^{11}$ In what follows, I'll assume that what forces movement of a wh-phrase in English is not semantic; perhaps it is (31).

To implement the idea that a wh-phrase introduces a variable bound by a higher operator, I'll adopt the approach to questions introduced by Hamblin (1973). On that view, the denotation of a wh-phrase is a set of alternatives. The denotation of what, for instance, is a set of alternative things. Alternatives combine semantically

8 See Hagstrom $(1998,2000)$ and Kishimoto (2005).

9 See Cheng (1991), but also Cable (2010) for some qualifications.

10 This is inspired by Chomsky (2000).

11 Cable makes use of two operators, one that resides in Complementizer position and another that is in construction with the phrase that moves. My discussion here conflates those two. 
in a point-wise fashion, so that the denotation of eat what, for instance, is a set of alternative VP meanings, each differing just in the thing that serves as object. If what introduces the alternatives nattoo, durian and balut, for instance, then \eat what will

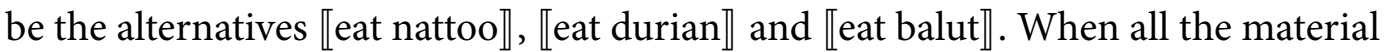
in a clause has been combined up in this way, what we'll have is a set of alternative propositions. This is what the $\mathrm{Q}$ morpheme combines with to form a question. On Hamblin's treatment, a question is a set of alternative propositions of a certain kind, and so the difference between what $\mathrm{Q}$ gets and what it produces is minimal. See Beck (2006) and Cable (2010) for discussion.

Now reconsider the multidominant representation of Andrews amalgams. If we add to it the elements of the account of wh-phrases just sketched, we get (32)

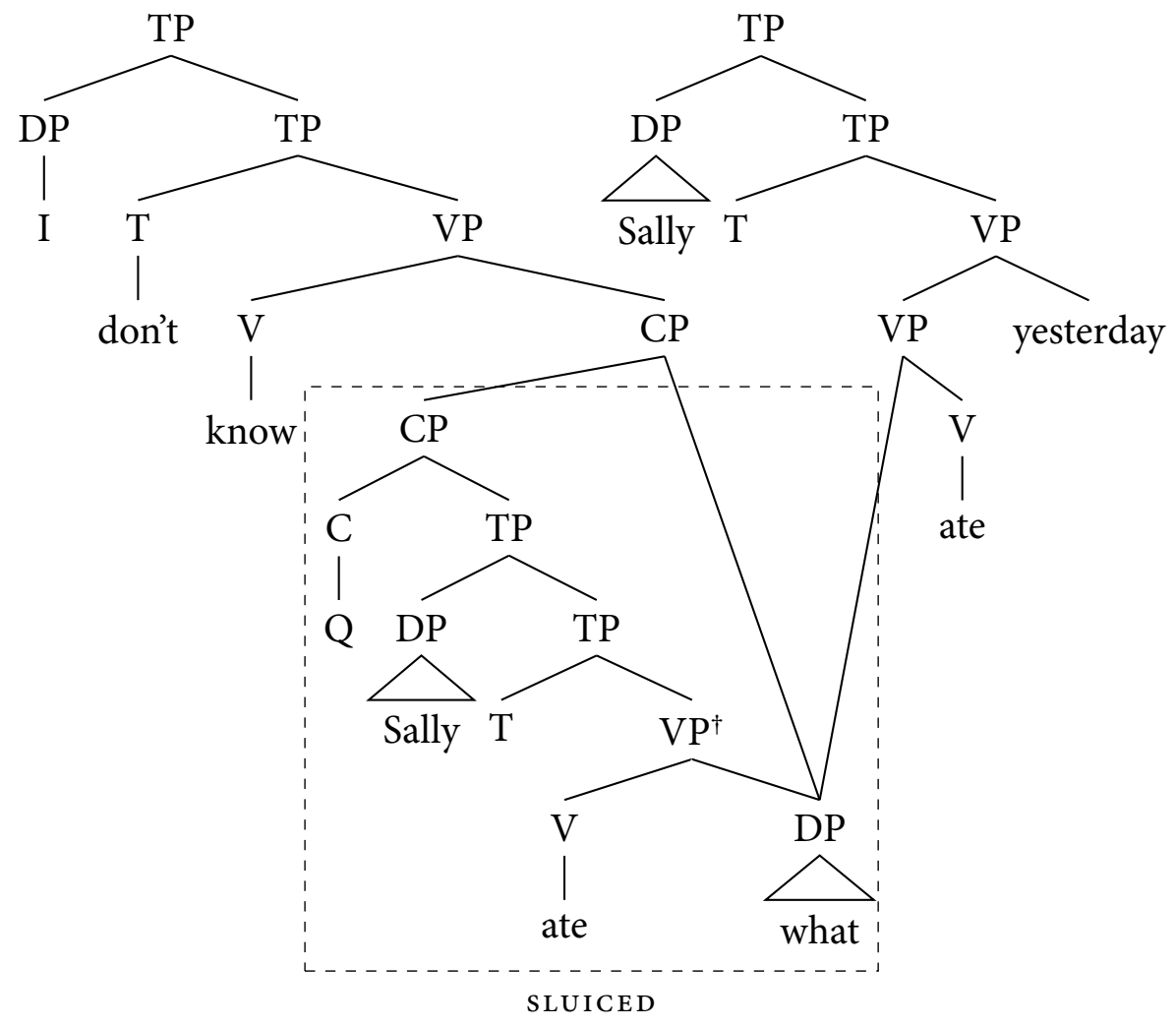

In (32), what is in three places. I'll step through these positions and describe how it is evaluated in each.

(33) Daughter of $\mathrm{VP}^{\dagger}$

a. Not pronounced here because (single) wh-phrases must be pronounced closer to Q (and because this is within the sluice).

b. Semantically interpreted as the object of ate. 
(34) Daughter of CP

a. Pronounced here because English requires the Specifier of a CP to be phonologically filled by a wh-phrase.

b. Not semantically interpreted here.

(35) Daughter of VP

a. Pronounced here for whatever reason the objects of transitive verbs must be overt in English.

b. Semantically interpreted as the object of ate.

The alternatives that what provides is used by Q to make the complement of know a question. Its semantic contribution to the interrupting clause, then, is as the term that generates the alternatives from which a question denotation is derived.

In the host clause, however, something different happens. We must assume that there is a silent operator which uses the alternatives generated by what to produce a meaning equivalent to one produced by something. A similar thing happens with the wh-phrases in Tlingit, the language that forms the backbone of Cable (2010)'s analysis, and Cable argues that in Tlingit sentences where wh-phrases get such an interpretation there is an existentially bound choice function that operates on the alternatives. Let us adopt a similar strategy for our case. I'll give an informal description of how it works.

The choice function, $\mathcal{F}$, takes a set of alternatives as its argument and returns one of those alternatives as its output.

(36) $\mathcal{F}(\mathrm{A})=a$, where $\mathrm{A}$ is a set of alternatives and $a$ is one of those alternatives.

Assume that clauses can contain a silent existentially quantified $\mathcal{F}$. If one of these is in the host clause of (32), this would produce a representation like (37). 
(37)

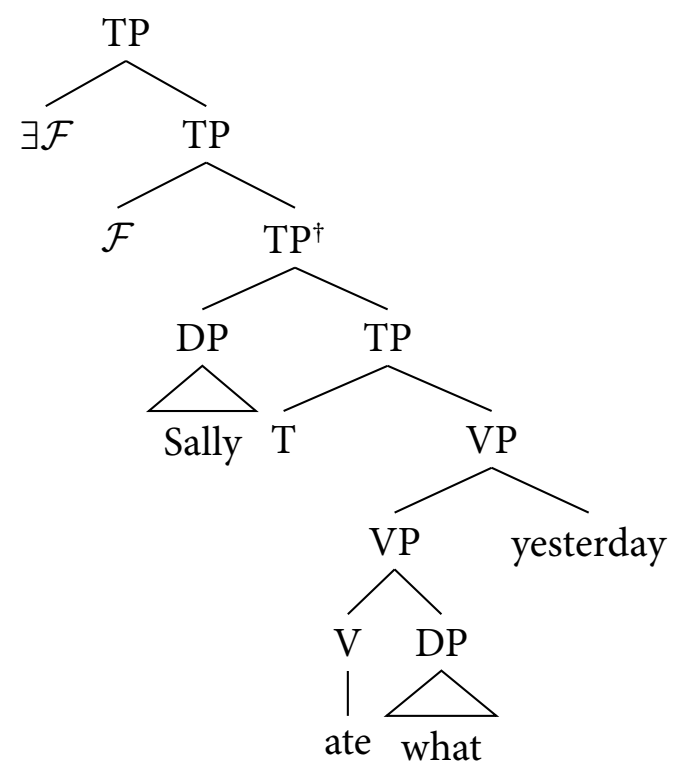

The meaning of $\mathrm{TP}^{\dagger}$ will be a set of alternatives of the form indicated in (38).

$$
\llbracket \mathrm{TP}^{\dagger} \rrbracket=\left\{\begin{array}{c}
\llbracket \text { Sally ate natto yesterday } \rrbracket \\
\llbracket \text { Sally ate durian yesterday } \rrbracket \\
\llbracket \text { Sally ate balut yesterday } \rrbracket \\
\vdots
\end{array}\right\}
$$

If we assume that the denotation of a clause is a description of a particular situation, perhaps the one under discussion, then the set in (38) can be understood to be a set of alternative descriptions of that situation. The root TP in (37) will have a meaning that is derived from letting $\mathcal{F}$ choose one of these alternatives. That meaning is paraphrased by (39).

(39) $\llbracket(37) \rrbracket=$ There is a way of choosing from $\left\{\begin{array}{c}\llbracket \text { Sally ate natto yesterday } \rrbracket \\ \llbracket \text { Sally ate durian yesterday } \rrbracket \\ \llbracket \text { Sally ate balut yesterday } \rrbracket \\ \vdots\end{array}\right\}$

(39) says that one of the ways of describing the situation is in the set of alternatives provided by $\llbracket \mathrm{TP}^{\dagger} \rrbracket$. That is truth functionally equivalent to the meaning of Sally ate something yesterday, ${ }^{12}$ and so this derives the desired meaning for the host clause.

What this analysis claims, then, is that the set of alternatives that a wh-phrase introduces can be used either to form a question or to form a declarative existential sentence. In the case of Andrews amalgams, both of these possibilities are exploited: the question meaning forms the sluice of the interrupting clause, and the declarative 
existential meaning is delivered by the host clause. If this is correct, it must be ensured that the existential meaning is not produced by wh-phrases outside of amalgams. It is not the case that a wh-in-situ, for instance, can be interpreted as anything but an interrogative phrase. Sentences like (40) do not have an interpretation like that produced for (41).

(40) What did Sally give to whom?

(41) What did Sally give to someone?

What makes amalgams different from cases like (40) is that the wh-phrase in the amalgam is in two different sentences, only one of which is as an interrogative. If we can derive (42), then we will correctly limit to amalgams the ability of a wh-phrase to be interpreted as a non-interrogative indefinite.

(42) A wh-phrase's denotation must always be part of the meaning of a question.

I don't know how to derive (42), but it seems likely to me that strengthening the relationship between $\mathrm{Q}$ and the determiner that expresses its morphology to something more semantic is in the right direction. See Beck (2006) for some techniques that might be exploited here.

Unlike Kluck's solution, this account provides an explanation for why Andrews Amalgams can be found with obligatorily transitive verbs: the wh-phrase serves as the object of those verbs. And it explains why the indefinite in the hosting clause can have wider scope than implicit arguments are able to. The scope of the wh-phrase in the host clause will be wherever the existentially bound choice function is inserted. Implicit arguments must get their existential force in some other way, a way that allows them only the narrowest of scopes. I do not know what existentially closes off the free variable introduced by implicit arguments, nor why that has the consequences it has for their scope. Nor do I know what determines where the existentially quantified choice function which I am suggesting interprets the alternatives introduced by whphrases can be. I cannot therefore provide an explanation for why these two things have the scopes they do. But unlike Kluck's account, mine can explain why they do not have the same scopes.

\section{Sluicing}

There are two important problems with the account just sketched. Both of these problems have to do with the shape that Andrews amalgams can have. One problem is that the account does not determine which of the two sentences that make up the amalgam is the host and which interrupts. The other problem is that the account does not force the interrupting clause to have a sluice in it. This section argues that these 
two problems are connected. The solution has the consequences for licensing ellipses that were advertised at the beginning of the paper.

The account in the previous section forces the two sentences that make up an Andrews amalgam to be linearized as one string. Contiguity requires that the shared material be as adjacent as possible to the sister it has in each of the sentences it stands. I argued that this drives the interrupting clause inside the host clause, putting it as close to the wh-phrase as possible.

In fact, Contiguity drives one of the sentences into the other, but it doesn't determine which sentence that is. Reconsider the structure we are entertaining for Andrews amalgams and let's walk through how Contiguity judges it.

(9) Contiguity

Assign a violation mark to a phrase if the strings assigned to each of its immediate daughters do not have an adjacent edge.

(43)

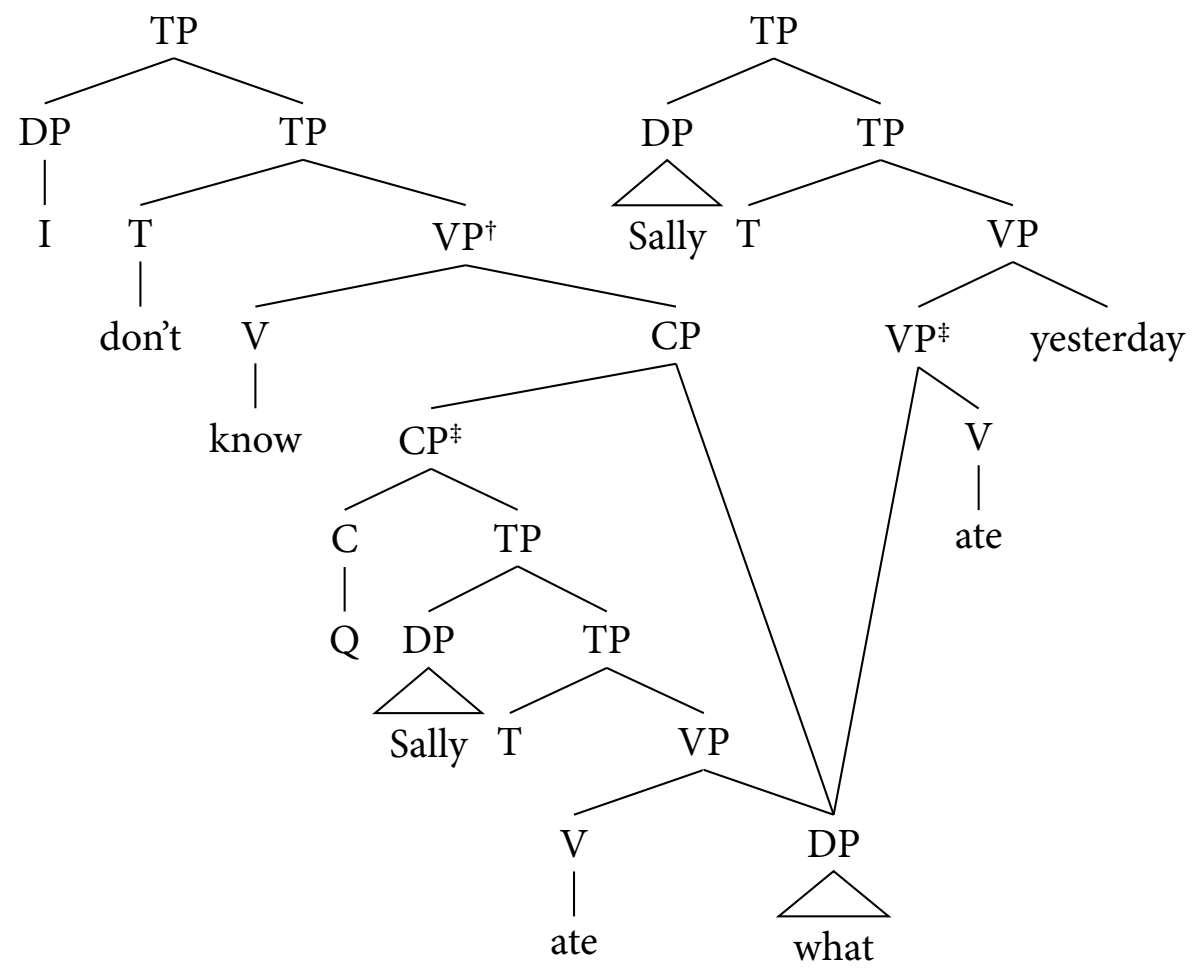

We can ignore what Contiguity would say about the phrases within $\mathrm{CP}^{\ddagger}$ because it is elided. Contiguity will assign one violation mark if the daughters of $\mathrm{VP}^{\ddagger}$ are not adjacent, that is if ate and what are not adjacent. And it will assign one violation mark if the daughters of $\mathrm{VP}^{\dagger}$ are not adjacent, that is if know and what are not adjacent. Because the other principles of English linearization require what to follow both ate 
and know, it is not possible for what to be simultaneously adjacent to both of them. Unavoidably, then, $\mathrm{VP}^{\ddagger}$ or $\mathrm{VP}^{\dagger}$ will trigger a violation of Contiguity.

All other violations of Contiguity are avoidable, however, and so the winning linearizations will be ones in which $\mathrm{VP}^{\dagger}$ alone violates Contiguity or ones in which $\mathrm{VP}^{\ddagger}$ alone violates Continguity. In the linearization that actually emerges, (44), $\mathrm{VP}^{\ddagger}$ violates it.

(44) Sally ate I don't know what yesterday.

But the linearization in (45), where only $\mathrm{VP}^{\dagger}$ violates Contiguity, is also allowed.

(45) I don't know Sally ate what yesterday.

This must be prevented. Something chooses (44) over (45); something specifies which clause is driven inside the other.

In Kluck (2011), this is connected to the observation that the clause which is linearized inside the other clause is understood to be the speaker's comment about the proposition denoted by the other clause. She does this by building this meaning into the operation that merges the interrupting clause into the host clause. The proposal here cannot make use of that idea, since the interrupting clause is not being subordinated to the host clause, but I would like to preserve Kluck's idea that these two facts are connected. Luis Vicente observes that in discourses there is an ordering on clauses of the sort that we see here too. The ordering in (46a) is much more natural than the ordering in (46b), for instance.

(46) a. Sally ate something yesterday. I don't know what.

b. I don't know what. Sally ate something yesterday.

Even when there isn't the anaphora invoked by the sluice in (46), there is a preference for putting the sentence that denotes the proposition about which you wish to comment before the sentence that denotes the comment.

(47) a. Satoshi ran the Philadelphia marathon faster than Paul Ryan could have. I am not surprised.

b. \# I am not surprised. Satoshi ran the Philadelphia marathon faster than Paul Ryan could have.

Let's assume, then, that the principles structuring a discourse have the effect described in (48).

(48) The left edge of $\mathrm{P}$ must precede the left edge of a clause that is a comment on $\mathrm{P}$.

This will correctly choose (44) over (45). 
The other problem with the account concerns Sluicing, and it's this problem that bears on the nature of the licensor for ellipsis. The problem is that an Andrews amalgam must have a sluiced clause in it. If (43) is pronounced with the material inside $\mathrm{CP}^{\ddagger}$ spoken, the result is ungrammatical.

(49) * Sally ate I don't know what Sally ate.

Moreover, If neither of the sentences that are brought together in an Andrews amalgam do not have material that can be sluiced, the result is ungrammatical.

Deriving this property is one of the central goals of Guimarães (2004). His proposal has two parts. He suggests a structure, slightly different from (43), that will ensure that the standard linearization schemes fail. Then he devises a linearization scheme purpose built for that structure that has the right outcome. I will adopt his structure, but suggest a different way of resolving the linearization problem it creates.

Guimaräes's structure aims to explain why (49) is ungrammatical. What is needed is something that prevents the sluiced material from being spoken. Note that in Andrews amalgams, the sluiced material is part of the same string which holds its antecedent. We could use this feature of amalgams to force sluicing if we could find a way of preventing the sluiced material from being pronounced in the same string as its antecedent. One way of achieving that goal in frameworks which allow multidominant phrase markers is to let the material which can only be pronounced once be the same material given two positions. Under normal circumstances, when a phrase has two positions in a phrase marker, the linearization algorithm cannot let the material associated with that phrase show up twice in the string. ${ }^{13}$ For instance, consider how the structure in (50) gets linearized.

(50)

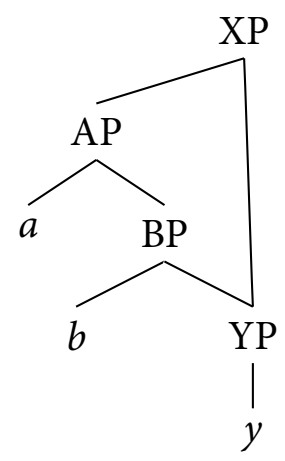

YP is an immediate daughter of both XP and BP. Imagine that the linearization statements for the structure that (50) illustrates are satisfied if $y$ precedes the material

13 See Nunes $(1999,1996,2004)$ for discussion of the special cases. The technique described here for preventing a double pronunciation of material in two positions is in its essentials the one proposed in Nunes's work. 
in AP or follows $b$. (YP, for instance, might be a wh-phrase that has moved in English, with $b$ representing a verb and XP representing a CP.) The linearization scheme will be blocked from allowing $y$ to both precede the material in AP and follow $b$, however. The strings that standard linearization schemes will permit are those in (51), but $\operatorname{not}(52)$.
(51) a. $y a b$
b. $a b y$
(52) yaby

(52) is prevented by Kayne (1994)'s Antisymmetry.

(53) Antisymmetry

If $\alpha$ precedes $\beta$ in a linearization, then $\beta$ cannot precede $\alpha$ in that linearization.

In (52), $y$ both precedes and follows $a$, and this is what Antisymmetry forbids. In general, then, there must be a mechanism that permits a structure like (50) to avoid a violation of Antisymmetry. There must be a mechanism that allows one of the positions a phrase occupies to be ignored by the linearization algorithm, yielding the licit possible linearizations in (51). Multidominant representations, then, yield licit strings only when something licenses a partial linearization of them, thereby avoiding violations of Antisymmetry.

Guimaräes exploits this method to explain the ungrammaticality of (52). He suggests that the host clause and the clause that is sluiced are the same clause. We can incorporate this suggestion into the analysis here with (54). 
(54)

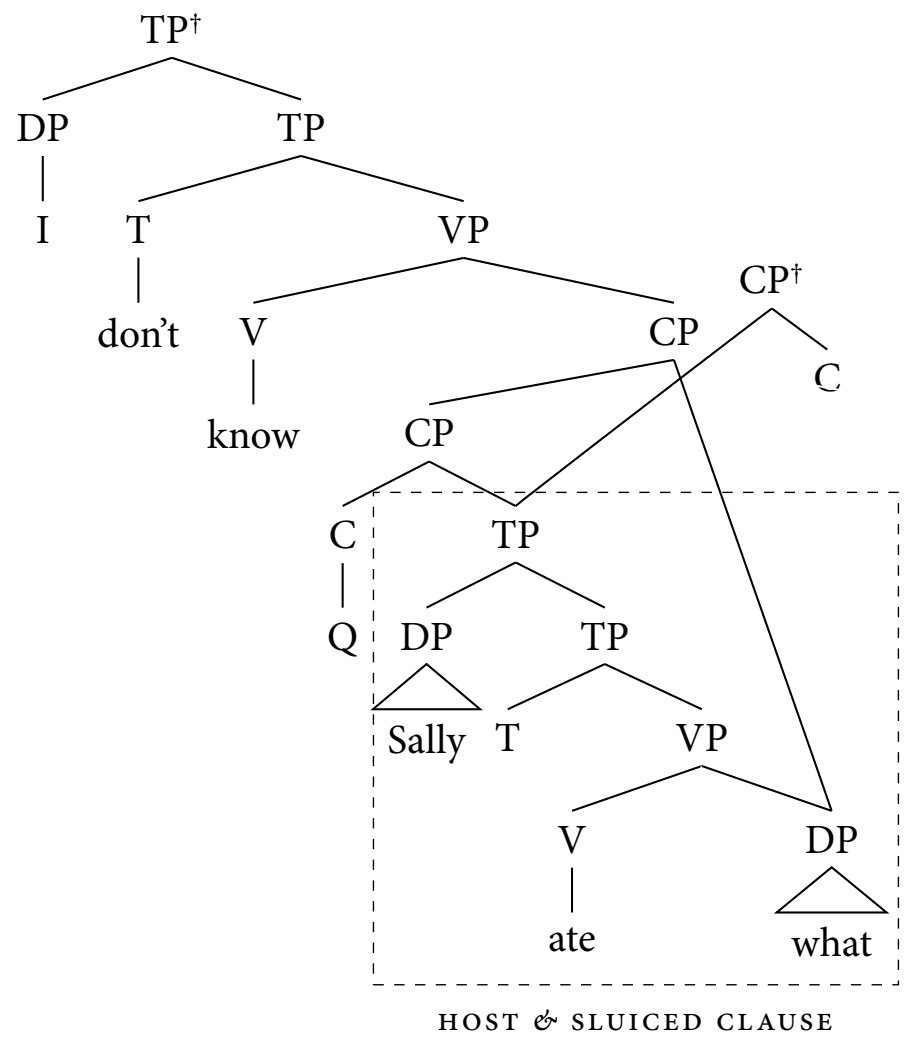

In (54), it is not the wh-phrase that is shared, but instead a TP containing that whphrase which is shared. This TP combines with the Complementizer heading the $\mathrm{CP}$ which know selects, and it combines with a Complementizer that forms the $\mathrm{CP}$ which constitutes the host clause. This shared TP will have the set of alternatives meaning described in the previous section (see (38) on p. 16). When that meaning is combined with the Complementizer holding $\mathrm{Q}$, the resulting $\mathrm{CP}$ will have the meaning of a question. When that denotation is combined with the complementizer that lies in the hosting clause, it will produce a $\mathrm{CP}$ with the meaning of a declarative existential sentence. This requires that the choice function, $\mathcal{F}$, which operates on the alternatives to produce this reading, be very high in the hosting clause. It cannot be in the shared part, but must instead reside in the complementizer or higher. ${ }^{14}$ The semantics sketched in the previous section, then, transfers over straightforwardly to $(54)$.

14 This predicts, correctly I believe, that the existential quantification in the hosting clause must be sentence wide. In the previous section, we saw that the existential quantification associated with the object in sentences like Sally hasn't eaten I don't know what yesterday need not be within the scope of negation. In fact, however, this existential quantification can't be within the scope of negation. 
So also do the effects of Contiguity. ${ }^{15}$ The boxed TP in (54) must be linearized so that its left edge precedes the left edge of $\mathrm{TP}^{\dagger}$. This, recall, is meant to follow from the ordering that seems natural for comments and the propositions they are comments on. Just as before, this pitches the VP headed by ate against the VP headed by know: only one of these can satisfy Contiguity. If the boxed TP must start the string, then letting the VP headed by ate violate Contiguity permits a linearization in which no other violations of Contiguity arise. That is the best linearization possible, and it corresponds, correctly, to Sally ate I don't know what.

Adopting (54), then, carries over all of the effects sketched in the previous section. But it also makes it possible to use Antisymmetry to block (45).

(45) Sally ate I don't know what Sally ate.

Sally and ate both precede and follow know, among other words, and Antisymmetry forbids this.

To avoid these violations of Antisymmetry, Guimarães (2004) devises an ingenious linearization algorithm that applies to old-fashioned phrase markers as well as ones like (54), and in both cases produces the right result. This algorithm is engineered so that anytime there is a structure such as (54), it will linearize the shared material so that it begins the string, and place the other clause in the correct interior position. That, as it turns out, is too powerful, however. As Kluck (2011) shows, Andrews amalgams are always built upon sluices. What is needed, then, is something that allows the Antisymmetry violation to be avoided only in contexts where Sluicing is allowed. Guimaräes's linearization scheme would allow Andrews Amalgams in other environments as well.

To see that Andrews amalgams are licensed only in environments where Sluicing is permitted, we need to know first what those environments are. Sluicing elides the TP part of questions, and nothing else. It distinguishes TPs embedded in indirect questions from TPs embedded in free relatives, for instance. That is responsible for the contrast in (55).

15 One thing that goes awry with (54), however, is a full treatment of the scope facts. The facts discussed in the previous section - that the wh-phrase is in the scope of both clauses and that the rest of the interrupting clause is not in the scope of the hosting clause - continues to be accounted for by (54). But (54) makes the perverse prediction that the hosting clause will be in the scope of the interrupting clause, and this seems false. Principle $\mathrm{C}$ effects are not triggered in (ib), and a bound interpretation of his in (ia) isn't possible.

(i) a. ${ }^{*} \mathrm{His}_{1}$ favorite child ate no father 1 can guess what.

b. Sally,'s daughter ate she $e_{1}$ can only guess what. 
(55) a. Mary ate something, and I'll tell you what Mary ate.

b. * Mary danced some time last week, and I danced when Mary danced.

As we've seen, interrupting clauses can contain indirect questions from which a TP has been dropped. But if the interrupting clause contains a free relative, then the TP inside it cannot drop.

(56) * Mary danced I'm pleased when.

This is perfectly general. Andrews amalgams only arise when the host clause matches a clause in the interrupting clause that has sluiced. What we're looking for is something that will allow Andrews amalgams only where sluices are permitted. ${ }^{16}$

We should conclude that the same thing which licenses Sluicing licenses the failure to linearize the shared TP in an Andrews amalgam in both of its positions, then. Suppose, for instance, that the question complementizer licenses Sluicing. For this complementizer to license both Sluicing and Andrews amalgams, it must have the effect described in (57).

(57) A term that licenses ellipsis allows its sister to not be submitted to the linearization algorithm.

When the sister to an ellipsis licensor is not submitted to the linearization algorithm, the words in that phrase are not assigned the positions in the resulting string that are associated with being in that particular position in the phrase marker. If the question complementizer is the licensor, for instance, then the words in the TP that is its sister will not be linearized so that they all follow the question complementizer. In the case of Sluicing, this has the effect of eliding that material. In the case of Andrews amalgams, this has the effect of allowing the material to be linearized according to its other position in the phrase marker. Because a violation of Antisymmetry would result if the shared material in an Andrews amalgam had to be linearized in both its positions, the ellipsis licensor is required to amnesty one of those positions from the linearization algorithm. This is why Andrews amalgams can only occur where sluices are licensed, and why the sluicing is required in Andrews amalgams.

If (57) is the correct way of describing the licensing condition on ellipsis, however, it does not fit with the ways described at the outset that couple the licensing condition

16 Michal Starke points out, however, that not all kinds of sluices are possible in Andrews amalgams, as the contrast in (i) illustrates.

(i) a. Sally ate some balut, but I don't know what else.

b. * Sally ate I don't know what else yesterday.

This particular case might follow from the requirement that else places on the antecedent of sluices. There is no antecedent in an Andrews amalgam. 
with a specification of its antecedence condition. If the licensing condition on ellipsis were necessarily coupled with a denotation that specified what its antecedent must be, then it would not be able to function grammatically in Andrews amalgams. There is no antecedent to the "elided" phrase in an Andrews amalgam. In an amalgam, the licensing condition on ellipsis is doing nothing more than allowing the phrase that is unspoken in one position to be spoken elsewhere.

These cases, then, speak on behalf of a theory of ellipsis which divorces the conditions which allow a phrase to be elided from the conditions that indicate how that elided phrase's meaning is recovered. I think this means that the way an elided phrase recovers its meaning is not given by a procedure dedicated to ellipsis. Andrews amalgams teach us that ellipsis is nothing more than allowing a phrase to go unpronounced in a particular position. The antecedence conditions that normally accompany that operation have nothing to do with it. They arise, I speculate, because the sentences that are partially pronounced will not otherwise secure a meaning. The antecedence conditions on ellipsis must be entirely reduced to something else, perhaps the conditions that hold of deaccented material.

\section{References}

Adger, David, and Gillian Ramchand. 2005. Merge and move: Wh-dependencies revisited. Linguistic Inquiry 36:161-193.

Beck, Sigrid. 2006. Intervention effects follow from focus interpretation. Natural Language Semantics 14:1-56.

Cable, Seth. 2010. The grammar of Q: Q-particles, Wh-Movement and Pied-Piping. Oxford University Press.

Cheng, Lisa Lai-Shen. 1991. On the typology of wh-questions. Doctoral Dissertation, Massachusetts Institute of Technology.

Chomsky, Noam. 2000. Minimalist inquiries: The framework. In Step by step: Essays on minimalist syntax in honor of Howard Lasnik, ed. Roger Martin, David Michaels, and Juan Uriagereka, 89-156. MIT Press.

Fiengo, Robert, and Howard Lasnik. 1972. On nonrecoverable deletion in syntax. Linguistic Inquiry 3:528.

Fox, Danny. 2000. Economy and semantic interpretation. Cambridge, Massachusetts: MIT Press.

Guimarães, Maximiliano. 2004. Derivation and representation of syntactic amalgams. Doctoral Dissertation, University of Maryland.

Hagstrom, Paul. 1998. Decomposing questions. Doctoral Dissertation, Massachusetts Institute of Technology, Cambridge, Massachusetts. 
Hagstrom, Paul. 2000. The movement of question particles. In Proceedings of the North East Linguistic Society, ed. Masako Hirotani, Andries Coetzee, Nancy Hall, and Jiyung Kim, 275-286. Rutgers University: Graduate Linguistic Student Association.

Hamblin, Charles. 1973. Questions in Montague grammar. Foundations of Language 10:41-53.

Hardt, Daniel. 1992. VP ellipsis and semantic identity. In Proceedings of the Stuttgart Ellipsis Workshop, ed. Steve Berman and Arild Hestvik. Stuttgart.

Hardt, Daniel, and Maribel Romero. 2004. Ellipsis and the structure of discourse. Journal of Semantics 21:375-414.

Katz, Jerrold J., and Paul Postal. 1964. An integrated theory of linguistic descriptions. Cambridge, Massachusetts: MIT Press.

Kayne, Richard S. 1994. The antisymmetry of syntax. Cambridge, Massachusetts: MIT Press.

Kishimoto, Hideki. 2005. Wh-in-situ and movement in Sinhala questions. Natural Language and Linguistic Theory 23:1-51.

Kluck, Marlies. 2011. Sentence amalgamation. Groningen: Landelijke Onderzoeckschool Taalwetenschap.

Kratzer, Angelika. 2005. Indefinites and the operators they depend on: From Japanese to Salish. In Reference and quantification: The Partee effect, ed. Gregory N. Carlson and Francis Jeffrey Pelletier, 113-142. CSLI Publications.

Lakoff, George. 1974. Syntactic amalgams. In Papers from the 1oth Regional Meeting of the Chicago Linguistic Society, ed. Michael Galy, Robert Fox, and Anthony Bruck, 321-344.

Lobeck, Anne. 1987a. Syntactic constraints on ellipsis. Doctoral Dissertation, University of Washington, Seattle.

Lobeck, Anne. 1987b. VP ellipsis in infinitives: Infl as a proper governor. In NELS, ed. J. McDonough and B. Plunkett, 425-441. GLSA.

Lobeck, Anne. 1992. Licensing and identification of ellipted categories in English. In Proceedings of the Stuttgart Ellipsis Workshop, ed. Steve Berman and Arild Hestvik. Stuttgart.

Merchant, Jason. 2001. The syntax of silence: sluicing, islands, and the theory of ellipsis. Oxford: Oxford University Press.

Nunes, Jairo. 1996. On why traces cannot be phonetically realized. In Proceedings of North East Linguistic Society, ed. Kiyomi Kusumoto, 211-226. Harvard University and MIT: Graduate Linguistic Student Association.

Nunes, Jairo. 1999. Linearization of chains and phonetic realization of chain links. In Working minimalism, ed. Samuel Epstein and Norbert Hornstein, 217-249. Cambridge, Massachusetts: MIT Press. 
Nunes, Jairo. 2004. Linearization of chains and sideward movement. Linguistic Inquiry Monographs. Cambridge, Massachusetts: MIT Press.

Riemsdijk, Henk van. 1998. Trees and scions - science and trees. In Festweb page for noam chomsky. MIT Press.

Riemsdijk, Henk van. 200o. Wh-prefixes, the case of wäsch in Swiss German. In Naturally! linguistic studies in honour of Wolfgang Ulrich Dressler, ed. Chris SchanerWolles, John Rennison, and Friedrich Neubarth. Torino: Rosenberg \& Sellier.

Riemsdijk, Henk van. 2006. Towards a unified theory of wh- and non-wh-amalgams. In In search of the essence of language science: festschrift for Professor Heizo Nakajima, ed. Yubun Suzuki, Mizuho Keiso, and Ken-ichi Takami, 43-59. Tokyo: Hitsuji Shobo.

Romero, Maribel. 2000. Antecedentless sluiced wh phrases and islands. In Ellipsis in conjunction, ed. Kerstin Schwabe and Ning Zhang, 195-220. Tübingen: Niemeyer.

Rooth, Mats. 1992. Ellipsis redundancy and reduction redundancy. In Proceedings of the Stuttgart Ellipsis Workshop, ed. Steve Berman and Arild Hestvik. Stuttgart.

Ross, John Robert. 1969. Guess who? In Chicago Linguistics Society, ed. Robert I. Binnick, Alice Davison, Georgia M. Green, and Jerry L. Morgan, 252-286. Chicago, Illinois.

Shimoyama, Junko. 2006. Indeterminate phrase quantification in Japanese. Natural Language Semantics 139-173:2.

Tancredi, Christopher. 1992. Deletion, deaccenting and presupposition. Doctoral Dissertation, Massachusetts Institute of Technology, Cambridge.

Tsubomoto, Atsuro, and John Whitman. 2000. A type of head-in-situ construction in English. Linguistic Inquiry 31:176-183.

de Vries, Mark. 2006. The syntax of appositive relativization: On specifying coordination, false free relatives, and promotion. Linguistic Inquiry 37:229-270.

Webber, Bonnie. 1978. A formal approach to discourse anaphora. Doctoral Dissertation, Harvard University.

Wilder, Chris. 1998. Transparent free relatives. ZAS Working Papers in Linguistics 10:191-199.

Zagona, Karen. 1988a. Proper government of antecedentless VPs in English and Spanish. Natural Language and Linguistic Theory 6:95-128.

Zagona, Karen. 1988b. Verb phrase syntax: A parametric study of English and Spanish. Dordrecht: Kluwer Academic Publishers. 